\title{
A newly recorded species, Sergentia kizakiensis (Tokunaga, 1940) (Diptera: Chironomidae), from Oriental China with DNA barcode
}

\author{
Qian Wang ${ }^{1}$, Hai-Jun $\mathrm{Yu}^{1}$, Xin-Hua Wang ${ }^{2}$, Xiao-Long Lin"* \\ ${ }^{1}$ Key Laboratory of Aquatic-Ecology and Aquaculture of Tianjin, College of Fishery, Tianjin Agricultural \\ University, Tianjin, 300384, China \\ ${ }^{2}$ College of Life Sciences, Nankai University, Tianjin, 300071, China \\ ${ }^{*}$ Corresponding author, E-mail: lin880224@gmail.com
}

\begin{abstract}
Sergentia kizakiensis (Tokunaga, 1940) is newly recorded from Oriental China. Here, adult males are redescribed and illustrated. Additionally, we provide a DNA barcode of S. kizakiensis from China.

\section{Introduction}

The lentic chironomid genus Sergentia includes 17 species known to Holarctic and Oriental regions (Papoucheva et al. 2003, Wülker et al. 1999, Yamamoto et al. 2019). Papoucheva et al. (2003) explored the phylogeny of Sergentia using molecular data, concluding that the genus appears to be monophyletic. Yamamoto et al. (2019) formally transferred the Japanese species Phaenopsectra kizakiensis to the genus Sergentia, documenting its synonymy. However, Sergentia is poorly studied in China, and with only two recorded species: Sergentia baueri and Sergentia prima. Recently, we found another Sergentia species from Oriental China, which was difficult to identify morphologically, especially considering the high morphological similarity among most species in the genus. Considering that DNA barcodes have proven efficient in species delimitation in chironomids (Anderson et al. 2013, Lin et al. 2015, Lin et al. 2018), we use DNA barcodes to confirm the taxonomic status of this unidentified Sergentia species from China.
\end{abstract}

Based on the material from China, adult males of Sergentia kizakiensis are redescribed and illustrated. A DNA barcode of $S$. kizakiensis from China is also included.

\section{Material and Methods}

Five adults were collected using a sweep net near an alpine lake from Oriental China. The material examined was mounted on slides, following the procedure outlined by Sæther (1969). Digital photographs were taken using a Nikon Digital Sight DS-Fil camera mounted on Nikon Eclipse 80i compound microscope at the Nankai University. All specimens were deposited in the College of Life Sciences, Nankai University (NKU), China. Morphological nomenclature in the description below follows Sæther (1980).

DNA amplifications of COI barcode sequences with the universal primers LCO1490 and HCO2198 (Folmer et al. 1994) followed methods outlined by Lin et al. (2015) and were carried out at the College of Fishery, Tianjin Agricultural University. PCR products were electrophoresed in 1.0\% agarose gel, purified and sequenced at BGI TechSolutions Co., Lit. (Beijing, China). Raw sequences were edited and assembled in SeqMan (DNASTAR, Madison, USA), and then uploaded on Barcode of Life Data systems (BOLD) (Ratnasingham and Hebert 2007, Ratnasingham and Hebert 2013) along with collateral information and an image.

\section{Sergentia (Baicalosergentia) kizakiensis (Tokunaga, 1940)}

Pentapedilum kizakiensis Tokunaga, 1940: 290 (as subgenus Phaenopsectra).

Phaenopsectra kizakiensis: Sasa \& Yamamoto, 1977: 313; Sasa, 1984: 54; Sasa \& Hirabayashi, 1991: 110; Sasa \& Suzuki, 2000: 179.

Sergentia kizakiensis: Yamamoto, 2010: 224; Yamamoto \& Yamamoto, 2014: 339; Yamamoto, Suzuki \& Yamamoto, 2019: 67 (as subgenus Baicalosergentia).

Stictochironomus kamiprimus Sasa \& Hirabayashi, 1991: 110.

Material examined. 5 ภิ $\widehat{\partial}$ (NKU: K5B28, K5B28, K5B42, K5B44; NKU \& BOLD Sample ID: K5B45), CHINA: Zhejiang Province, Taizhou City, Tiantai County, Huadingshan Mountain, $29.2523^{\circ} \mathrm{N}, 121.091^{\circ} \mathrm{E}$, 1000m a.s.1., 12.IV.2011, Sweep net, leg. X.L. Lin. 
Diagnostic characters. The male imago can be distinguished from known species of the genus by having wings covered with microtrichia; $\mathrm{LR}_{1}>1$; mid tarsomere 1 with 10-14, 12 sensilla chaetica; superior volsella curbed only at tip, without lateral seta.

\section{Description}

Male $(\mathrm{n}=5)$

Total length 5.68-7.08, $6.24 \mathrm{~mm}$. Wing length 3.40-4.20, $3.71 \mathrm{~mm}$. Total length/wing length $1.60-1.78$, 1.68. Wing length/length of profemur 2.62-2.89, 2.78 .

Coloration. Head, legs and abdomen dark brown; wing brown; thorax dark brown.

Head. AR 2.49-3.38, 2.83. Ultimate flagellomere 0.98-1.19, $1.04 \mathrm{~mm}$ long. Temporal setae 16-21, 19 including 3-6, 4 inner verticals; 11-13, 11 outer verticals and 2-4, 3 postorbital. Clypeus with 23-38, 31 setae. Tentorium 185-215, $196 \mu \mathrm{m}$ long, 62-80, $68 \mu \mathrm{m}$ wide. Palpomere lengths (in $\mu \mathrm{m}$ ): 70-79, 75; 70-92, $84 ; 189-220,202 ; 198-251,223 ; 253-317,275 . \mathrm{L}^{\text {th }} / 3^{\text {rd }} 1.29-1.44,1.36$.

Wing (Fig. 1A). VR 1.02-1.03. Brachiolum with 2-3, 2 setae. R with 46-56, 52 setae, $\mathrm{R}_{1}$ with 48-58, 53 setae, $\mathrm{R}_{4+5}$ with 120-130, 126 setae, $\mathrm{M}_{1+2}$ with 69-89, 80 setae, $\mathrm{M}_{3+4}$ with 54-73, 64 setae, $\mathrm{Cu}_{1}$ with 18-31, 24 setae, remaining veins bare. Cell $\mathrm{r}_{4+5}, \mathrm{~m}_{1+2}$ with and $\mathrm{m}_{3+4}$ with numerous setae. Squama with 28-30, 28 setae.

Thorax (Fig. 1B). Dorsocentrals 17-28, 22; acrostichals 4-5, 5; prealars 6-8, 6. Scutellum with 24-30, 26 setae.

Legs. Scale on fore tibia rounded, 50-75, $60 \mu \mathrm{m}$ long, sometimes with a small lateral spine. Mid tibia with one 28-32, $30 \mu \mathrm{m}$ long spur; spurs of hind tibia $28-33,30 \mu \mathrm{m}$ and $13-16,15 \mu \mathrm{m}$ long. Width at apex of fore tibia 75-88, $81 \mu \mathrm{m}$, of mid tibia 63-90, $78 \mu \mathrm{m}$, of hind tibia 75-95, 83 $\mu \mathrm{m}$. Mid tarsomere 1 with 10-14, 12 sensilla chaetica. Lengths (in $\mu \mathrm{m}$ ) and proportions of legs as in Table 1.
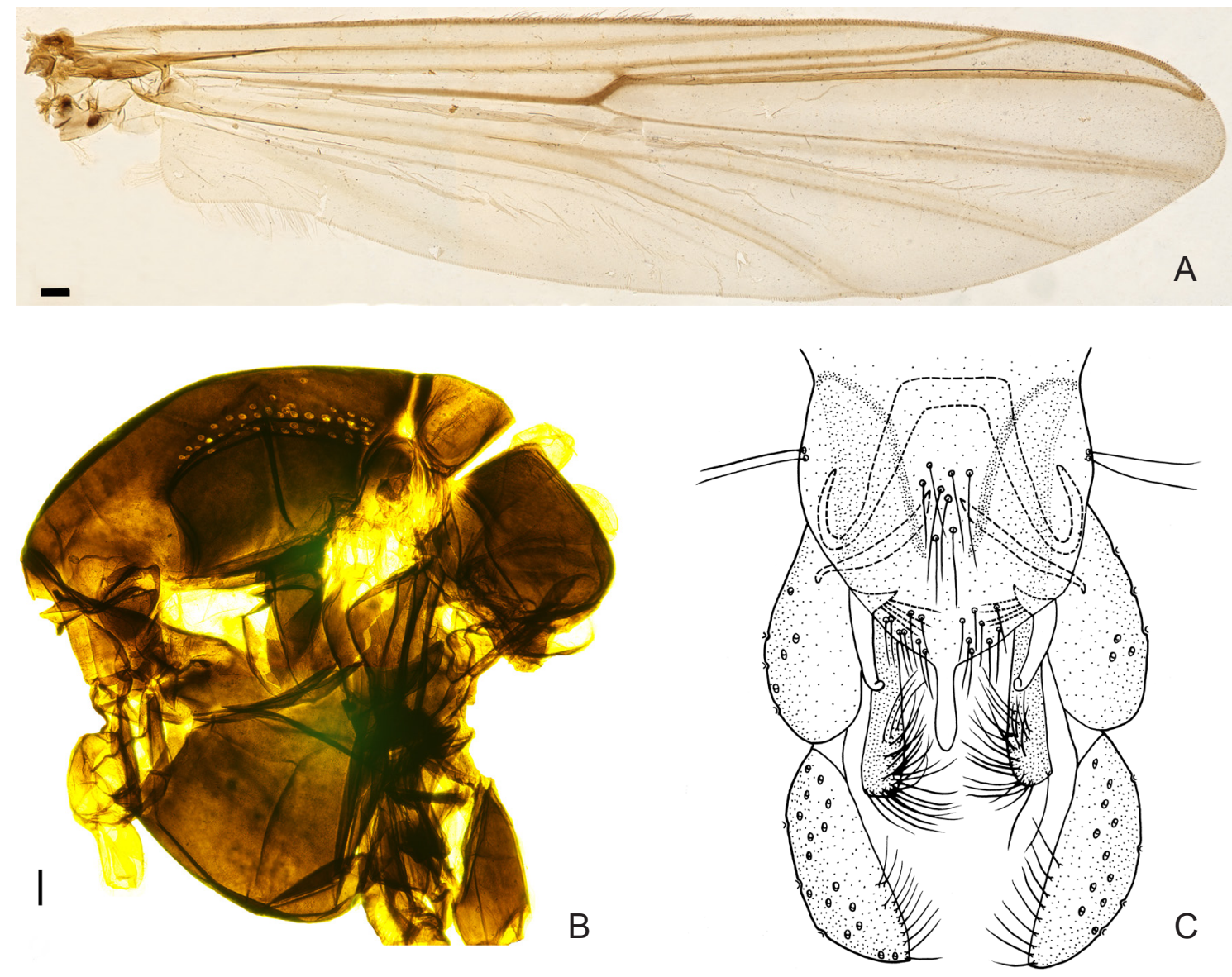

Figure 1. Sergentia (Baicalosergentia) kizakiensis (Tokunaga, 1940). A) wing; B) thorax; scale bar $=100 \mu \mathrm{m} ; \mathrm{C}$ ) hypopygium. 
Table 1. Lengths (in $\mu \mathrm{m}$ ) and proportions of legs of Sergentia kizakiensis (Tokunaga, 1940), male $(\mathrm{n}=5)$.

\begin{tabular}{lccc}
\hline & $\mathrm{P}_{1}$ & $\mathrm{P}_{2}$ & $\mathrm{P}_{3}$ \\
\hline $\mathrm{fe}$ & $1250-1475,1335$ & $1325-1600,1405$ & $1475-1775,1575$ \\
$\mathrm{ti}$ & $1250-1450,1335$ & $1250-1475,1325$ & $1500-1825,1630$ \\
$\mathrm{ta}_{1}$ & $1425-1755,1546$ & $725-875,783$ & $1075-1350,1185$ \\
$\mathrm{ta}_{2}$ & $875-1075,945$ & $500-600,540$ & $700-875,743$ \\
$\mathrm{ta}_{3}$ & $640-750,676$ & $380-440,398$ & $500-640,552$ \\
$\mathrm{ta}_{4}$ & $500-580,522$ & $240-280,258$ & $320-380,340$ \\
$\mathrm{ta}_{5}$ & $250-290,260$ & $160-190,173$ & $180-210,195$ \\
$\mathrm{LR}$ & $1.14-1.19,1.36$ & $0.57-0.58,0.58$ & $0.72-0.74,0.73$ \\
$\mathrm{BV}$ & $1.68-1.79,1.74$ & $2.54-2.65,2.59$ & $1.50-2.50,2.40$ \\
$\mathrm{SV}$ & $1.67-1.79,1.71$ & $3.50-3.59,3.54$ & $2.70-2.77,2.73$ \\
$\mathrm{BR}$ & $7.80-8.89,8.39$ & $2.9-7.86,6.56$ & $7.71-10.7,8.86$ \\
\hline
\end{tabular}

Hypopygium (Fig. 1C). Tergite IX with 4-10, 8 median setae. Anal point with rounded apex. Laterosernite IX with 2-3, 2 setae. Superior volsella digitiform, with four inner setae, and without lateral setae. Phallapodeme 115-155, $134 \mu \mathrm{m}$ long. Transverse sternapodeme 75-105, $85 \mu \mathrm{m}$ long. Gonocoxite 233-273, 249 $\mu \mathrm{m}$ long. Gonostylus $\mu \mathrm{m}$ 172-216, $192 \mu \mathrm{m}$ long. Inferior volsella straight, 145-175 $\mu \mathrm{m}$ long, with 24-30, 26 setae. HR 1.26-1.35, 1.30. HV 3.03-3.58, 3.25.

Distribution. China, Japan.

Remarks. Sergentia kizakiensis is redescribed here based on additional material from China. Based on morphological characters, Chinese specimens fit well with the original description (Tokunaga 1940), but a few differences are noted: Chinese specimens have a higher AR (2.49-3.38), and 3-7 inner setae on superior volsella, as compared to Japanese specimens (Sasa 1984, Sasa and Suzuki 2000), described with $\mathrm{AR}=2.3-2.4$ and superior volsella with 3-7 inner setae. Sergentia kizakiensis includes two DNA barcodes clustering into two BINs in BOLD: the BIN (BOLD: ADY6241) from China with a genetic divergence of $4.65 \%$ to the BIN (BOLD: ACH8232) from Japan.

\section{Acknowledgements}

Financial support from the National Natural Science Foundation of China (31672264, 31301908, 31900344) and the China Postdoctoral Science Foundation Grant (2018M640227) are acknowledged with thanks. We would like to thank two anonymous reviewers for their suggestions and comments.

\section{References}

Anderson, A.M., Stur, E. and Ekrem, T. 2013. Molecular and morphological methods reveal cryptic diversity and three new species of Nearctic Micropsectra (Diptera: Chironomidae). - Freshwater Science 32: 892-921. DOI: http://dx.doi.org/10.1899/12-026.1

Folmer, O., Black, M., Hoeh, W., Lutz, R. and Vrijenhoek, R. 1994. DNA primers for amplification of mitochondrial cytochrome $c$ oxidase subunit I from diverse metazoan invertebrates. - Molecular Marine Biology and Biotechnology 3: 294-299.

Lin, X.-L., Stur, E. and Ekrem, T. 2015. Exploring genetic divergence in a species-rich insect genus using 2790 DNA Barcodes. - PLoS ONE 10: e0138993. DOI: http://dx.doi.org/10.1371/journal.pone.0138993

Lin, X.-L., Stur, E. and Ekrem, T. 2018. DNA barcodes and morphology reveal unrecognized species of Chironomidae (Diptera). - Insect Systematics \& Evolution 49: 329-398. DOI: http://dx.doi. org/10.1163/1876312X-00002172

Papoucheva, E., Proviz, V., Lambkin, C., Goddeeris, B. and Blinov, A. 2003. Phylogeny of the endemic baikalian Sergentia (Chironomidae, Diptera). - Molecular Phylogenetics and Evolution 29: 120-125.

Ratnasingham, S. and Hebert, P.D.N. 2007. BOLD: The Barcode of Life Data System (www.barcodinglife. org). - Molecular Ecology Notes 7: 355-364. DOI: http://dx.doi.org/10.1111/j.1471-8286.2006.01678.x

Ratnasingham, S. and Hebert, P.D.N. 2013. A DNA-based registry for all animal species: the barcode index 
number (BIN) system. - PLoS One 8: e66213. https://dx.doi.org/10.1371/journal.pone.0066213

Sæther, O.A. 1969. Some Nearctic Podonominae, Diamesinae, and Orthocladiinae (Diptera: Chironomidae). - Bulletin of the Fisheries Research Board of Canada 170: 1-154.

Sæther, O.A. 1980. Glossary of chironomid morphology terminology (Diptera: Chironomidae). - Entomologica Scandinavica Supplement 14: 1-51.

Sasa, M. 1984. Studdies on chironomid midges in kakes of Nikko National Park. Part II. Taxonomic and morphological studies on the chironomid species collected from lkes in the Nikko National Park. - Research Report from the National Institute for environmental Studies 70: 17-215.

Sasa, M. and Hirabayashi, K. 1991. Studies on the chironomid midges (Diptera, Chironomidae) collected at Kamikochi and Asama-Onsen, Nagano Prefecture. - Japanese Journal of sanitary Zoology 42: 109-128.

Sasa, M. and Suzuki, H. 2000. Studies on the chironomid species collectied at five localties in Hokkaido in September, 1998 (Diptera, Chironomidae). - Tropical Medicine 42: 175-199.

Sasa, M. and Yamamoto, M. 1977. A checklist of Chironomidae recorded from Japan. - Japanese Journal of sanitary Zoology 28: 301-318.

Tokunaga, M. 1940. Chironomidae from Japan (Diptera). XII New or little-known Ceratopogonidae and Chironomidae. - The Philippine Journal of Science 72: 255-311.

Wülker, W., Kiknadze, I., Kerkis, I. and Nevers, P. 1999. Chromosomes, morphology, ecology and distribution of Sergentia baueri, spec. nov., S. prima Proviz \& Proviz, 1997 and S. coracina Zett., 1824. - Spixiana 22: 69-81.

Yamamoto, M. 2010. Chironomidae of Japan. VII. Chironominae. - Bunnichi Sogo-syuppan 158-259.

Yamamoto, M. and Yamamoto, N. 2014. Family Chironomidae. In Saigusa, T. (Ed.) Catalogue of the Insects of Japan, Vol.8, Part 1. Diptera (Nematocera - Brachycera Aschiza). The Entomological Society of Japan, pp. 237-362.

Yamamoto, N., Suzuki, H. and Yamamoto, M. 2019. Taxonomic Notes on Several Japanese Chironomids (Diptera) Described by Dr. M. Sasa $(\dagger)$ and his coauthors. - Japanese Journal of Systematic Entomology 25: $63-72$.

Article submitted 15. October 2019, accepted by Alyssa M. Anderson 1. December 2019, published 19. December 2019. 